This is a pre-print of an article published in Language Acquisition. The final authenticated version is available online at:

https://www.tandfonline.com/eprint/KX3NPPJEDUKQJD8KX6C9/full?target=10.1080/10489223.2021.1982948

Please cite the published paper as:

Durand-López, E. M. (2021). L2 within-language morphological competition during spoken word recognition. Language Acquisition, 1-17. https://doi.org/10.1080/10489223.2021.1982948

\title{
L2 within-language morphological competition during spoken word recognition
}

\author{
Ezequiel M. Durand-López
}

Rutgers University

\author{
Address for correspondence \\ Correspondence concerning this article should be addressed to Ezequiel M. Durand-López, 15 \\ Seminary Place-West, 5185, New Brunswick, NJ 08901. Email address: \\ durand.ezequiel@ rutgers.edu
}




\begin{abstract}
Bilinguals recognize words with shared morphology and phonology cross-linguistically (i.e., cognates) faster than words that do not have these characteristics. Moreover, higher phonological overlap in cognates enhances the said effects, which suggests that phonology eases word recognition. However, it is currently unclear whether words compete purely morphologically before spoken word recognition within-language, and whether proficiency in the L2 modulates the degree of morphological competition. Spanish monolinguals and English L2 learners of Spanish with varying L2 proficiency completed an auditory lexical decision task in Spanish. Stimuli were phonological sequences of Spanish words prior to a recognition point (e.g., /mark/ in /marko/) whose activated cohorts were minimal pairs. Some pairs were morphologically related (e.g., huerto, 'vegetable patch' versus huerta, 'vegetable garden') whereas some others had no morphological relationship (e.g., marco, 'frame' versus marca, 'brand'). Results showed that both groups processed solely phonological competitors in a similar way as they did with morphological competitors. Taken together, these findings suggest that morphological relatedness does not modulate neither L1 nor L2 spoken word recognition prior to a recognition point when speakers listen to words in absence of context. In addition, the findings suggest that the $\mathrm{L} 2$ recognition architecture is qualitatively similar to that of native speakers.

Keywords: morphological competition, spoken word recognition, L2 Spanish, morphological processing, phonological overlap
\end{abstract}




\section{L2 within-language morphological competition during spoken word recognition}

Individuals are exposed to an uncountable number of words daily, by either reading or listening to them. In the latter case, words that we listen to vary in a number of ways: they can be either from our first (L1) or second (L2) language, they can be produced with some phonetic variation, there can be noise that may prevents us from listening to the whole word, and the lexical frequency of a word may facilitate or complicate the lexical retrieval process. All these possibilities have been evaluated and explained in a myriad of spoken word recognition models, most of which focus on the perceptual characteristics of the input and how the signal maps onto the listener's phonological representations. One common claim among spoken word recognition models is that there are several stages in speech processing before accessing the meaning of a lexical item. These models argue that the process begins with the activation of phonological representation based on the acoustic properties of the input. In addition, the degree of match between the acoustic characteristics of the stimuli and the phonological representation determines lexical activation. If the input has not reached a linear phonological point that is specific to a given word known by the hearer, multiple candidates sharing these phonological characteristics then compete for recognition (Gaskell \& Marslen-Wilson, 1997, 1999, 2002; Marslen-Wilson, 1987, 1990; Marslen-Wilson \& Tyler, 1980). Previous studies indicate that these activated candidates compete in terms of their phonological overlap within a speaker's L1 (e.g., Blumenfeld \& Marian 2011; Marian \& Spivey, 2003) or across a bilingual speaker's language systems (e.g., Blumenfeld \& Marian 2007; Marian, Chabal, Bartolotti, Bradley, \& Hernandez, 2014). However, whether the activated candidates compete not only phonologically but also in terms of their word structure before recognition remains unclear. Words sharing the same root, thus being related in their meaning and word structure, might also compete with one 
another. This has been suggested in cross-linguistic studies (e.g., Marian et al., 2014), but the stimuli used were cognates (i.e., words sharing word structure and phonology). Thus, it is unclear whether (a) it is phonology or morphology which makes the activated candidates compete for recognition, and (b) words can compete in their morphology within language (and not only cross-linguistically) in the L1 and in the L2. The present study aims at exploring the said two matters in adult Spanish monolinguals and English L2 learners of Spanish using a lexical decision task.

Spoken word recognition models are traditionally divided into two groups: distributed (e.g., the Distributed Cohort Model per Gaskell \& Marslen-Wilson, 1997) and localist models (e.g., the Neighborhood Activation Model per Luce \& Pisoni, 1998; Shortlist per Norris, 1994; TRACE model per McClelland \& Elman, 1986). While localist accounts posit that each node represents one representational unit, distributed models argue that the processor maps the speech signal onto different levels of distributed representations, such as phonology and semantics, thus considering word meaning an important part of spoken word recognition. Given that the present investigation aims at elucidating morphological (i.e., form and meaning) effects, distributed models will be prioritized.

The Cohort Model (Marslen-Wilson, 1987, 1990; Marslen-Wilson \& Tyler, 1980) was one of the first accounts to explain how native speakers recognized L1 words auditorily. This account has undergone various modifications since its inception. The original Cohort Model posited that, first, phonemes in the speech signal are mapped onto existing phonological sequences of words in the listener's lexicon. These words, known as cohorts, are activated or discarded based on linear phonological sequence matching. After discarding a given number of words in the lexicon based on acoustic cues in the input, listeners finally reach a word 
recognition point, thus selecting a specific word. Finally, features other than phonology, such as syntactic or semantic characteristics, are integrated.

This first proposal within the cohort framework was largely criticized by studies confirming that both child (e.g., Altvater-Mackensen \& Mani, 2013) and adult (e.g., Wingfield et al., 1997) speakers are able to recognize words that do not completely match a phonological sequence stored in the lexicon. In a second version of the Cohort Model, phonological mismatches and lexical frequency were incorporated to account for the fact that frequent words are recognized faster than infrequent ones (Marslen-Wilson, 1990). Although most models of spoken word recognition also propose phonological competition among word candidates, these differ in various aspects with the original Cohort Model. First, both the TRACE (McClelland \& Elman, 1986) and the Shortlist (Norris, 1994) accounts assume that word onset does not constrain word recognition. Rather, phonological sequences that match existing representations but that are embedded in a word can activate multiple phonological competitors in the lexicon. However, candidates matching the word onset have a priority of final selection over other competitors because of inhibitory effects on them. Second, not only phonology but also prosody participates in the activation and discard of competitors in models such as Shortlist. More specifically, syllable stress can serve as a cue for selecting a specific candidate (e.g., Spanish /'papa/ 'potato' versus /pa'pa/ 'father'). Finally, the TRACE model, unlike the Cohort Model, includes feedback support from the lexicon to decipher the input. This incorporation speeds up and enhances the accuracy of the final interpretation of the speech signal.

The role of morphology on spoken word recognition is less clear than that of phonology. Most models do not extend the concept of competition to morphology or make predictions about morphological relatedness in speech processing. Currently, it is not clear whether words that are 
morphologically related through their root (e.g., Spanish huert-o 'vegetable patch' and huert-a 'vegetable garden', which share the same stem, huert-, which carries the meaning of the two words, and only differ in their gender, represented by the suffix) are processed differently than words that do not have any morphological competitor available in the lexicon (e.g., Spanish tall$o$ 'the stalk of a plant' and talla- $a$ 'clothing size', which do not share any morphological units, as tall- in tallo and tall- in talla are two distinct, albeit homophones roots), as morphology may be activated in parallel to phonology. In the case of morphological relatedness, both stems carry the same meaning. Therefore, these effects, if they exist, could be considered to be a special case of semantic relatedness effects, namely morphologically-induced semantic competition, or simply morphological competition. Although most accounts do not make explicit references to morphology, the last theoretical modification of the Cohort Model, namely the Distributed Cohort Model (Gaskell \& Marslen-Wilson, 1997, 1999, 2002), does include semantics in the word recognition process. This is so because access to semantic information might reduce the likelihood of activating words that do not fit semantically in a sentence. The main assumption of this account is that spoken word recognition operates by mapping phonetic features onto abstract representations of phonology and semantics, which operate in parallel. The speech processing architecture has two layers: a layer that takes the representation of the onset, nucleus and coda in the input and a hidden output layer that connects to a set of phonological features and a set of semantic features in a given word. As the speech signal unfolds, the architecture activates phonological and semantic representations. The semantic node contains a blended meaning of the phonological candidates prior to a recognition point. The clarity of the blended meaning depends on the semantic relatedness of the candidates. However, it is unclear in the model whether each phonological candidate has access to a separate blended meaning or whether there 
is only one unit containing the blended meaning of the competitors that is linked to all candidates. Finally, this model predicts that the level of activation and the degree of semantic relatedness effects are modulated by the amount of candidate words. More specifically, words with fewer candidates will have higher activation and enhanced semantic relatedness effects.

The vast majority of studies researching semantic competition effects have been conducted using visual stimuli without exploring morphological competition. These studies found that different types of semantic competition modulate visual lexical processing. These effects include animacy (animate nouns are harder to process than inanimate nouns; e.g., Sagarra \& Herschensohn, 2011), semantic neighborhood density (a greater number of semantic competitors facilitate word recognition; e.g., Buchanan, Westbury \& Burgess, 2001), or concreteness (concrete nouns are easier to recognize than abstract ones; e.g., Danguecan \& Buchanan, 2016). Evidence for semantic competition effects in spoken word recognition is limited, as studies are scarce (e.g., Goh, Yap, Lau, Ng, \& Tan, 2016; Mirman \& Magnuson, 2009). Early behavioral studies gathered evidence in favor of the Distributed Cohort Model with native speakers (e.g., Gaskell \& Marslen-Wilson, 1999, 2002; Moss, 1997). For example, Gaskell and Marslen-Wilson (2002) conducted an auditory priming study in which native speakers of English listened to a phonological sequence partially matching only two candidates (e.g., /kæptın/ activates both 'captain' and 'captive'). This condition did not result in faster lexical decisions on words that were semantic competitors to one of the word candidates (e.g., commander). On the other hand, when participants listened to a phonological sequence partially matching only one possible candidate, they were faster at making a lexical decision on a semantically related word. The researchers concluded that semantic effects may emerge only when one candidate is activated. This is because a greater number of phonological competitors 
entails blended semantic representations of the activated phonological forms. On the other hand, L1 studies using suffixed words with multiple morphological competitors as stimuli in auditory lexical decision tasks suggest that morphological competition effects arise before the signal reaches a complex uniqueness point and after it reaches a regular uniqueness point. This effect emerges because in between these two stages, all competitors share some degree of morphological relatedness (e.g., Winther Balling \& Baayen, 2008).

Spoken word recognition models that include semantics, such as the Distributed Cohort Model, have also received criticism. For example, Norris, Cutler, McQueen, \& Butterfield (2006) compared form priming with conceptual priming. In a series of experiments, they found semantic priming effects (e.g., date-time), inhibitory effects for embedded phonological primes in sentences (e.g., sedate-date), but they failed to find phonological-semantic priming effects in embedded words (e.g., sedate-time). The authors claim that phonological and conceptual representations are separate, independent constituents in the spoken word recognition process, as conceptual representations are activated after phonological representations.

Considering the many different processes in spoken word recognition described above, it is clear that this process is far from being trivial for monolingual speakers. The same task can indeed be much more complex for bilinguals, as they must deal with the daunting task of discarding and selecting similar-sounding items from more than one language. This parallel activation during receptive processing has been found to occur even when bilinguals are engaged in their dominant language mode (e.g. Blumenfeld \& Marian, 2007). Several bilingual models of lexical access and spoken word recognition have been proposed in the last decades. The Bilingual Cohort Model (Blumenfeld \& Marian, 2007; Marian, 2000) extends the assumptions of the revised Cohort Model (Marslen-Wilson, 1990) to bilingual populations. According to this 
bottom-up proposal, words across languages activate in parallel as bilinguals listen to input. This results in a bilingual cohort which is progressively reduced as acoustic information unfolds until a word is selected. This model, however, does not incorporate the most recent claims about a semantic layer within the Distributed Cohort Model (Gaskell \& Marslen-Wilson, 1997), and thus does not predict any within- or cross-language semantic competition effects. One theoretical account that does include semantics in the bilingual lexical access process is the Revised Hierarchical Model (Kroll \& Stewart, 1994; Kroll, Van Hell, Tokowicz, \& Green, 2010). This account argues that the L2 learners' linguistic system is comprised of three elements: the L1 lexicon, the L2 lexicon, and a common conceptual level. Access to the conceptual level while processing L1 words is privileged, as links between the L1 lexicon and the conceptual level are strong. On the other hand, links between L1 and L2 words are stronger than the conceptual links between the concept and L2 words for low proficient L2 speakers. As proficiency increases, the links between the conceptual level and L2 words is stronger, and semantics can be directly accessed through the L2.

Most studies exploring bilingual lexical competition have focused on phonological competition, either within (e.g., Blumenfeld \& Marian 2011; Marian \& Spivey, 2003) or across languages (e.g., Blumenfeld \& Marian 2007; Marian et al., 2014). Morphological competition effects, on the other hand, have been examined mainly cross-linguistically through cognates. Several studies with visual lexical decision tasks have found cognate facilitation effects, such that bilinguals recognize cognates more easily than non-cognates (e.g., Rosselli, Ardila, Jurado, \& Salvatierra, 2014). In addition, this effect seems to be greater for cognates that are phonologically identical compared to those that share fewer phonological characteristics (e.g. Dijkstra, Miwa, Brummelhuis, Sappelli, \& Baayen, 2010). This suggests that it might be 
phonological competition, rather than morphological competition, that ease cross-linguistic word recognition.

The past spoken word recognition literature has addressed many phenomena that are now well established in the field, such as within- and cross-language phonological competition. Nonetheless, several critical aspects about L1 and L2 spoken word recognition remain unanswered. First, most studies have investigated competition effects during spoken word recognition with native speakers, but few have explored whether L2 learners present the same effects than native speakers while processing L2 words. Moreover, it is unclear whether proficiency in the L2 modulates these competition effects. Proficiency is known to modulate a myriad of linguistic processes in the L2, including morphological processing (e.g., Coughlin \& Tremblay, 2015), morphosyntactic processing (e.g., Alemán Bañón, Fiorentino \& Gabriele, 2018) and phonological processing (e.g., White, Titone, Genesee \& Steinhauser, 2017). Proficiency might also affect the building of a spoken word recognition architecture in the L2, especially considering that lexical representations are not as specified for beginner learners than for their near-native peers who might, in turn, resemble native speakers of the target language in their processing of spoken words.

Second, most spoken word recognition studies have explored how multiple phonological competitors affect word recognition, but very few studies have focused on whether words can also compete in terms of their morphological structure. The few studies that investigated morphological and semantic competition in bilingual spoken word recognition did so by observing cognate facilitation effects. However, these words share both phonological and morphological characteristics across languages, thus morphology has not been studied in isolation from phonology. In addition, some studies have suggested that the cognate facilitation 
effect is greater the more phonological overlap across items in question (e.g. Dijkstra, Miwa, Brummelhuis, Sappelli, \& Baayen, 2010). Therefore, it is not clear whether it is only phonology that affects spoken word recognition, or whether morphology can also compete while recognizing isolated words. Third, as mentioned above, the past literature has focused on L2 cross-linguistic competition, but the role of L2 within-language competition is unclear. This matter is important because spoken word recognition models predict certain outcomes for withinlanguage competition effects for native speakers but not for bilinguals, and bilingual models describe the said effects on cross-linguistic competition, but not on L2 within-language competition.

\section{The study}

The goal of the present study was to examine whether morphology affects how Spanish monolinguals and English L2 speakers of Spanish recognize L1 and L2 spoken words, respectively. This was explored through an auditory lexical decision task containing a unique set of Spanish lexical items. Stimuli were phonologically and phonetically identical, but they only differed in their gender, which changes the word's last phoneme. Otherwise stated, these words had the very same recognition point and share all the phonological linear features. In addition, some of these minimal pairs shared their morphological stem, thus being semantically related (e.g., huerto 'vegetable patch', huerta 'vegetable garden'), while other Spanish minimal pairs did not share any morphological similarity (e.g., marco 'frame', marca 'brand'). Also, both phonological and morphophonological competitors have an identical number of candidates activated prior to the word recognition point: two (one masculine and one feminine candidate), which is of utmost importance, as an experiment employing lexical items with these characteristics can test claims of specific spoken word recognition models, such as the 
Distributed Cohort Model (Gaskell \& Marslen-Wilson, 1997, 2002). More specifically, as it was mentioned earlier, this model claims that semantic relatedness effects arise solely when there is only one phonological candidate left to recognize the word. This is so because the semantic contents of more than one activated candidate are blended. In the Spanish stimuli selected in the present study, morphological competitor pairs have very similar meanings, as they share the same stem. If these meanings were blended, then morphological relatedness effects, if they exist, should still emerge.

In sum, the present study is one of the first exploratory steps in examining potential morphological relatedness effects on within-language L1 and L2 spoken word recognition. This is examined with the Spanish language, as it offers a particular set of lexical items that are phonologically identical but differ in their morphological relatedness. The findings of the current study may be informative about (a) whether L1 models should include a semantic layer to account for the spoken word recognition process, (b) whether L2 learners possess a similar recognition architecture to that of native speakers, and (c) whether L2 learners' recognition architecture suffers any change as they further advance on the acquisition of the L2.

\section{Method}

The tasks were conducted in the following order: two screening tasks (a language background questionnaire and a Spanish proficiency test), the auditory lexical decision task, and the vocabulary test. Monolingual participants were exempt from completing the Spanish proficiency test and the vocabulary task. All tasks were explained and conducted in Spanish.

\section{Participants}

One hundred and six right-handed participants, of which 80 late English L2 learners of Spanish (31 beginners, 22 intermediates and 27 advanced) and 26 Spanish monolingual speakers 
took part in the study. Participants were undergraduate or graduate students in a North American (L2 learners) or South American (Spanish monolinguals) university. All were between 18 and 55 years old $(M=22.76, S D=6.16)$. Participants indicated in a language background questionnaire that they had not spent more than six weeks in foreign-language country, and L2 learners began learning Spanish after puberty. Beginners were enrolled in a fourth semester Spanish class, intermediates were minoring or majoring in Spanish, and advanced L2 learners were enrolled in a graduate program in Spanish literature and culture. Spanish monolinguals were born and raised in Argentina, had studied an L2 in middle school and high school but had not continued studying it upon finishing mandatory education. Finally, all participants reported having normal hearing.

\section{Screening tasks}

In the Language Experience and Proficiency Questionnaire, (LEAP-Q; Marian, Blumenfeld, \& Kaushanskaya, 2007) L2 learners stated that they began acquiring Spanish after puberty $(M=14.1, S D=1.1$ years of age $)$. In addition, all of them were born and raised in the United States and were not exposed to Spanish at home. In contrast and based on the LEAP-Q, monolinguals were born and raised in Argentina and had not studied any L2 besides that of the requirement in the mandatory school years. Finally, participants indicated in the LEAP-Q that they had not spent more than six weeks in foreign-language country.

In order to measure L2 speakers' proficiency in Spanish, an abridged version of the Diploma de Español como Lengua Extranjera (DELE) was administered. L2 participants read sentences and a short text in Spanish and filled in the blanks with one of four options. Correct answers received one point. The cut-off points for the different proficiency groups were as follows: 0-29 for beginners, 30-39 for intermediates and 40-50 for advanced L2 learners (same cut-off points used in most studies with L2 learners of Spanish; e.g., Slabakova et al., 2012). A 
one way ANOVA showed a main effect of proficiency on DELE scores, $F(2,79)=188.52, p<$ .05. Pairwise comparisons were adjusted for multiple comparisons using the Scheffé posthoc test. Intermediate's DELE mean scores $(M=33.14, S D=3.00)$ were significantly higher than those of the beginner group $(M=19.41, S D=6.54), p<.001$, and significantly lower than those of advanced L2 learners $(M=44.46, S D=3.02), p<.001$, which were, in turn, significantly higher than those of their beginning L2 learner peers, $p<.001$.

\section{Auditory lexical decision task}

Participants completed an auditory lexical decision task in Spanish containing 150 items. There were 6 practice trials, 48 items that belonged to the present study and 96 remaining items that pertained to other two experiments whose results are not reported herein. The latter type of items served as distractors for the present study. Distractors were of two types. The first type included 48 items (24 real words and 24 pseudowords) that were sound sequences activating Spanish verbs. These items were minimal pairs differing in the length of the vowel (e.g., /sa:lt/ as in salto "I jump", and /salt/ as in saltó "he jumped"). The second type included 48 items (24 real words and 24 pseudowords) that were sound sequences activating words of different lexical categories prior to a recognition point (e.g., /tard/ activates both tarde 'late', an adjective, and tardar 'to take time', a verb). The distractors are not expected to affect the processing of the critical items in the present study in any manner, as none of the distractors shared any semantic, morphological or phonological relationship with any of the critical items.

Participants sat in front of a computer, wore noise-cancelling headsets, and were told to decide as fast and as accurately as possible whether the sequence of sounds they heard was part of one or more real word(s) in Spanish. They pressed a yes button for sequences that matched real Spanish words and a no button for sequences that did not match any Spanish words (e.g., 
/bark/ is part of both barco 'ship' and barca 'little ship', but /birk/ is not present in any Spanish word). The computer recorded their reaction times (RTs) and accuracy for every word. All sound files were recorded through a computerized voice using the Watson Text to Speech software (Santiago, Singh \& Sri, 2017) which provided each word recording with the acoustic characteristics of an adult male.

Experimental items were $50 \%$ of sound sequences that were embedded in more than one real Spanish word prior to a recognition point (e.g., /pwert/ is present in puerto 'harbor' and puerta 'door') (24 items) and 50\% of sequences that were not part of Spanish words, namely pseudowords (24 items). All pseudowords followed possible Spanish phonotactic rules (see Keuleers \& Brysbaert, 2011 for recommendations on not using nonwords in lexical decision tasks). Also, a t-test for independent samples showed no statistically significant differences on phonotactic probability between experimental words and pseudowords $t(46)=.23, p=.941$. Spanish real sound sequences matched the phonological beginning of 24 different pairs of twosyllable, inanimate nouns that were phonologically identical but differed in its grammatical gender, which was expressed in the last phoneme (e.g., /mark/ was the sound sequence prior to the recognition point of both marco-masc and marca-fem). These minimal pairs, therefore, were within-language phonological competitors that shared the same word recognition point (i.e., the last phoneme of the word). In addition, half of these minimal pairs were morphological competitors, while the other half did not share any morphological relation (see the Appendix for the complete list of pairs activated by the experimental sound sequences). Morphological competitors had a closely related meaning (e.g., bolso-masc means 'purse', whereas bolsa-fem means 'bag'). Phonological competitors, on the other hand, had two very different meanings (e.g., mango-masc means 'mango', while manga-fem means 'sleeve'), as they did not share the 
morphological stem, but only the same phonological sequence. Items in each list were pseudorandomized so that words from the same condition never occurred in a row (i.e., sequences activating nouns with morphologically related and unrelated competitors).

Experimental words were matched for a handful of variables affecting RTs, including syllable number (two syllables), lexical category (inanimate nouns), word recognition point (last phoneme), surface frequency, phonotactic probability, and phonological neighborhood density. Surface frequency was measured using the LEXESP corpus of Spanish (Sebastián-Gallés, Martí, Carreiras, \& Cuetos, 2000). A t-test for independent samples indicated that there was no statistically significant difference of surface frequency between morphologically related $(M=$ $14.51, S D=11.11)$ and morphologically unrelated nouns $(M=19.01, S D=16.87), t(46)=1.09$, $p=.081$. Also, the surface frequency of masculine $(M=14.31, S D=13.12)$ and feminine $(M=$ $14.71, S D=9.27)$ morphologically related competitors was comparable, $t(22)=.088, p=.26$, as well as that of masculine $(M=20.05, S D=21.07)$ and feminine $(M=17.96, S D=12.22)$ morphologically unrelated competitors, $t(22)=.298, p=.073$. The Phonotactic Probability Calculator of Spanish (Vitevitch \& Luce, 2004) was employed to measure the phonotactic probability of experimental words and pseudoword. The sum of all the phoneme probabilities and all the biphone probabilities was taken as the general phonotactic probability score for each word. Two t-tests for independent samples revealed no significant differences in phonotactic probability between words $(M=1.31, S D=.32)$ and pseudowords $(M=1.33, S D=.31), t(46)=$ $.23, p=.941$, or between morphologically related $(M=1.30, S D=.35)$ and unrelated $(M=1.32$, $S D=.31)$ nouns, $t(22)=.12, p=.456$. Finally, it was important to control for neighborhood density, as models of L1 spoken word recognition (e.g., the Neighborhood Activation model per Luce \& Pisoni, 1998) and word recognition studies with bilinguals (e.g., Meade, Midgley, 
Dijkstra, \& Holcomb, 2018) both suggest that words with a greater number of neighbors are harder to process. Phonological neighborhood density in Spanish was measured through the Neighborhood Calculator of Spanish (Vitevitch, Stamer, \& Kieweg, 2012). A t-test for independent samples showed that morphologically related nouns were not significantly different than morphologically unrelated nouns in terms of phonological neighborhood density, $t(41.92)=$ $1.78, p=.082$. In order to address the possibility that the phonological neighborhood density for activated words in the L1 (i.e., English) might affect the processing of critical words in the L2 (i.e., Spanish), the neighborhood density of the most common English translations for the Spanish experimental words was calculated using the Neighborhood Density calculator of English (Vitevitch \& Luce, 2016). A t-test for independent samples revealed no significant differences in phonological neighborhood density between Spanish and English words, $t(94)=$ $.02, p=.388$.

\section{Vocabulary test}

L2 speakers completed a translation recognition task containing all experimental items across conditions. The aim of this task was to confirm that the participants knew the meaning of the experimental words used in the main experimental task. Participants matched the real Spanish words with their English translations and were given one point for each correct match.

\section{Results}

The data cleaning procedure followed that of other spoken word recognition studies (e.g., Goh et al., 2016; Pexman, Heard, Lloyd, \& Yap, 2017). First, incorrect responses were eliminated ( $n=205$; mean accuracy was $89.26 \%$ ). Second, RTs faster than $200 \mathrm{~ms}$ or slower than $3000 \mathrm{~ms}$ were removed. The elimination of latencies affected $1.2 \%$ of the dataset $(n=25)$. 
Finally, raw RTs were standardized using a z-score transformation. Descriptive statistics for real words are found in Table 1.

\section{Table 1}

Means and SD in ms for RTs and accuracy across groups

\begin{tabular}{|c|c|c|c|c|c|c|c|c|}
\hline & \multicolumn{4}{|c|}{ RTs } & \multicolumn{4}{|c|}{ Accuracy } \\
\hline & \multicolumn{2}{|c|}{$\begin{array}{c}\text { Morphologically } \\
\text { related }\end{array}$} & \multicolumn{2}{|c|}{$\begin{array}{c}\text { Morphologically } \\
\text { unrelated }\end{array}$} & \multicolumn{2}{|c|}{$\begin{array}{c}\text { Morphologically } \\
\text { related }\end{array}$} & \multicolumn{2}{|c|}{$\begin{array}{c}\text { Morphologically } \\
\text { unrelated }\end{array}$} \\
\hline Group & $M$ & $S D$ & $M$ & $S D$ & $M$ & $S D$ & $M$ & $S D$ \\
\hline Beginners & 714.75 & 280.15 & 710.56 & 315.88 & 85.77 & 35.00 & 81.27 & 39.08 \\
\hline Intermediates & 762.95 & 318.28 & 721.34 & 330.47 & 91.30 & 28.24 & 89.59 & 30.60 \\
\hline Advanced & 729.98 & 259.94 & 731.82 & 308.68 & 92.27 & 26.75 & 89.35 & 30.90 \\
\hline Natives & 557.32 & 202.32 & 580.73 & 285.02 & 94.49 & 22.86 & 90.61 & 29.22 \\
\hline
\end{tabular}

A generalized linear mixed effects model (GLMM) with group (Spanish monolinguals, beginners, intermediates, and advanced L2 learners) and morphological relatedness (related, unrelated) as fixed effects and their possible interaction was fit to the accuracy data. The model included subject and item as random factors using the glmer function in the lme4 package (Bates $\&$ Maechler, 2009). The model revealed a main effect of group, $\chi^{2}(3, N=106)=11.23, p=.01$. Pairwise comparisons were adjusted for multiple comparisons using the Bonferroni posthoc test. Spanish monolinguals were significantly more accurate than beginners ( $p=.01, d=1.21)$, but there was no significant difference in accuracy between natives and intermediates $(p=1, d=$ $.41)$, natives and advanced L2 learners $(p=1, d=.29)$, beginners and intermediates $(p=.24, d=$ $.80)$, or beginners and advanced L2 learners $(p=.08, d=.92)$. On the other hand, the model did not find a main effect of morphological relatedness, $\chi^{2}(1, N=106)=0.23, p=.62$, or a 
significant group $\mathrm{x}$ morphological relatedness interaction, $\chi^{2}(3, N=106)=1.61, p=.65$. See Figure 1 for the visual representation of these effects.

\section{Figure 1}

Boxplot showing the quartiles (including outliers) of RTs in ms for the different conditions and groups.

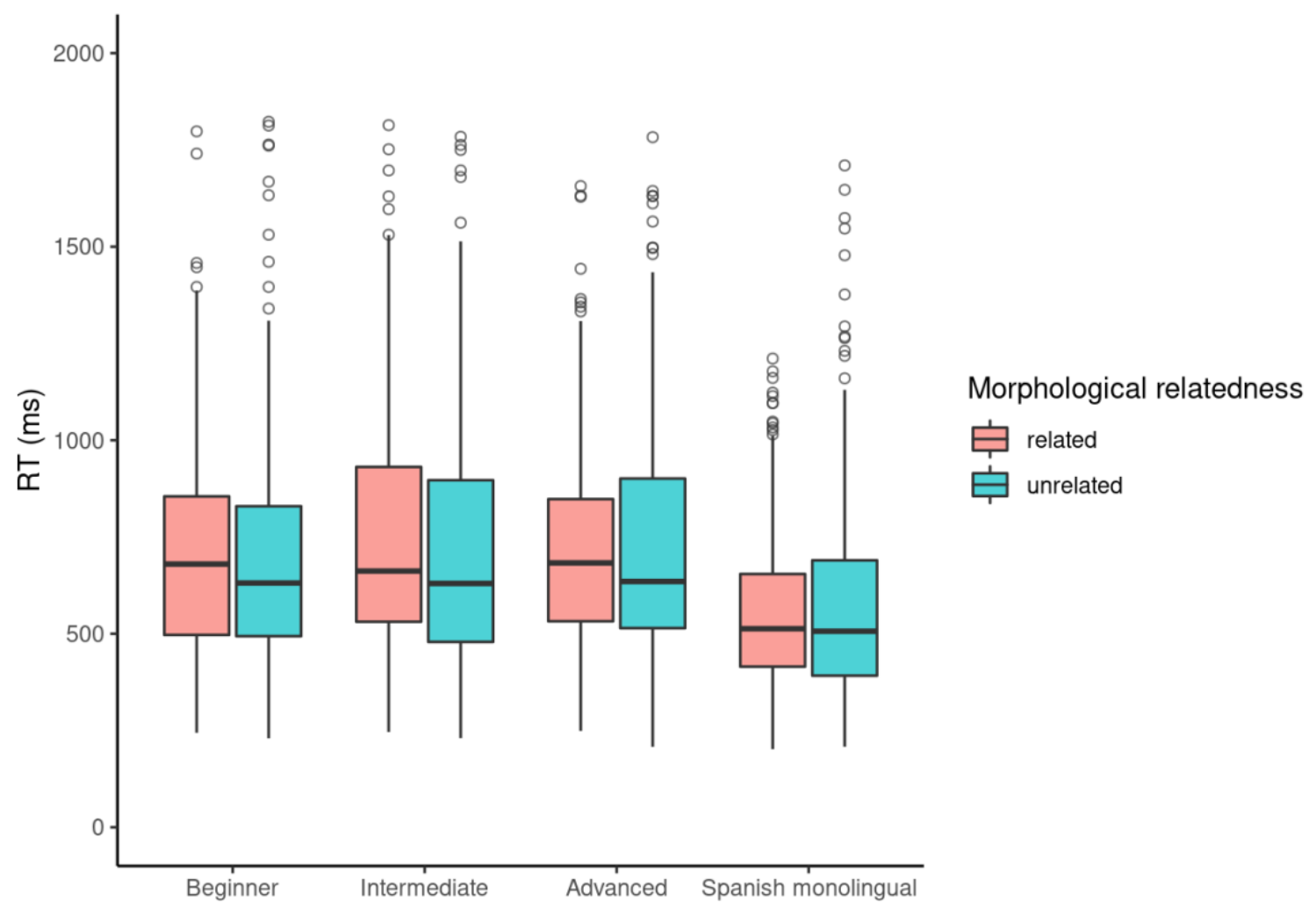

Another GLMM with group and morphological relatedness as fixed factors and subject and item as random factors was run on participants' RTs. Results revealed a significant main effect of group, $\chi^{2}(3, N=106)=28.38, p=.00$. Bonferroni-corrected pairwise comparisons revealed that native speakers were significantly faster than beginner $(p<.001, d=.72)$, intermediate $(p<.001, d=.75)$ and advanced L2 learners $(p<.001, d=.74)$. The model did not detect, however, a significant main effect of morphological relatedness, $\chi^{2}(1, N=106)=0.03, p$ 
$=.84$, or a significant interaction between group and morphological relatedness, $\chi^{2}(3, N=106)=$ $6.06, p=.10$. The effects of group and morphological relatedness on RTs can be found in Figure 2.

\section{Figure 2}

Boxplot showing participants' accuracy (in percentage) for the different conditions and groups.

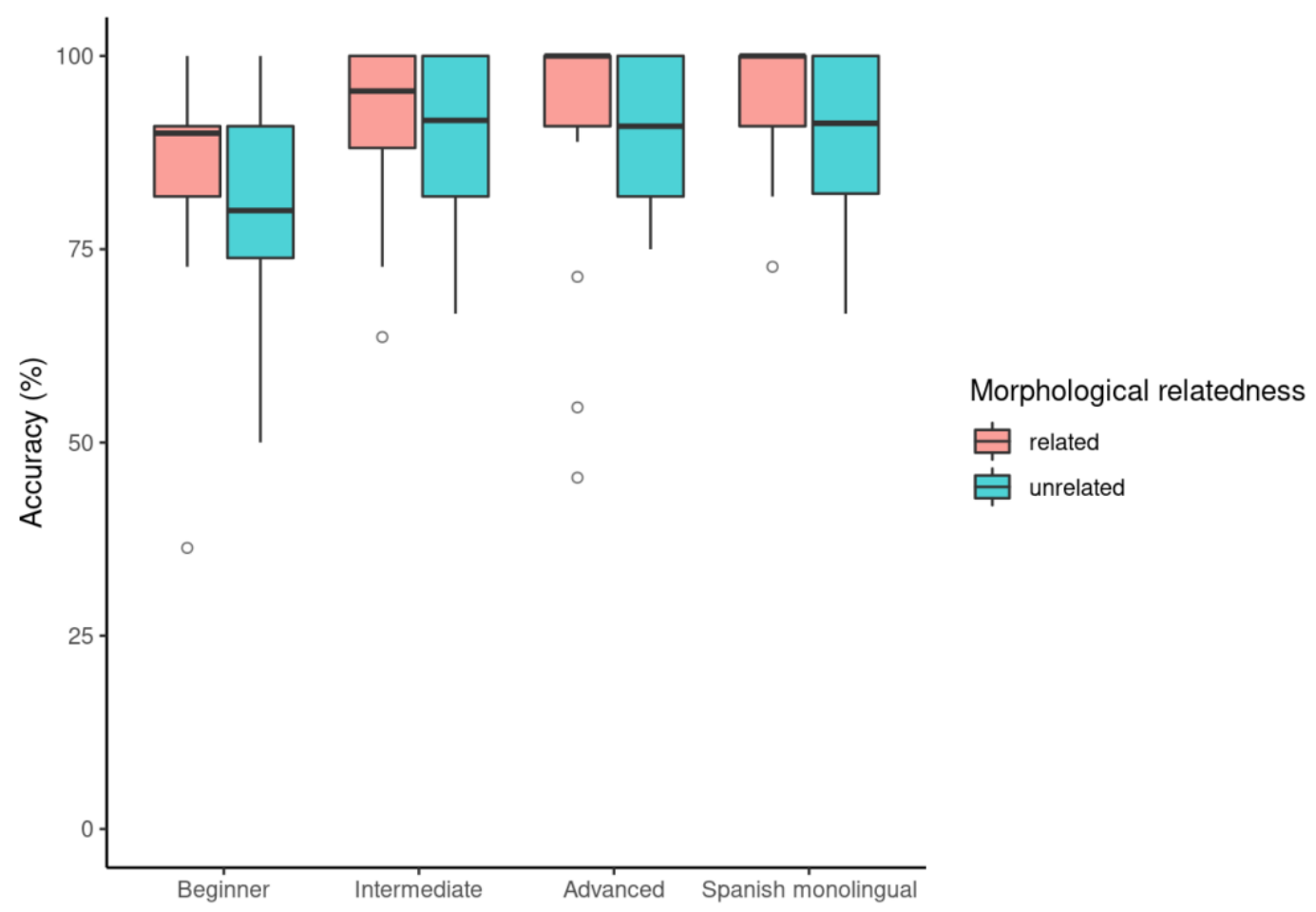

\section{Discussion}

The present study explored whether spoken words compete not only phonologically but also morphologically in Spanish monolinguals and English L2 learners of Spanish in their L1 and L2, respectively. This matter is relevant for several reasons: (a) Previous studies assessed the role of morphology in spoken word recognition through cognates, but the morphological variable was confounded with that of phonological overlap; (b) the potential effects of morphology in lexical competition have been assessed cross-linguistically, but not within-language; (c) it is unclear whether L2 learners possess the same recognition architecture in the L2 as their native 
speaker peers in their L1 with regard to morphology, and (d) the question of whether proficiency in the L2 modifies this structure by including or eliminating any potential role of morphology remains unanswered. In addition, this study tested distributed and localist L1 spoken word recognition models which predict different outcomes for the role of semantics. Morphological relatedness effects were assessed through a unique set of Spanish items, which are phonologically identical, have the same recognition point, have only one phonological competitor, and half of them also had a morphological competitor. It was assumed that a significant difference in RTs between phonological minimal pairs that are morphologically unrelated and phonological minimal pairs that are also morphologically related would indicate that morphological competition effects emerged.

Online data from this study shows that both Spanish monolinguals and English L2 learners of Spanish took a similar amount of time to recognize sound sequences activating morphologically related pairs than morphologically unrelated ones. Within the L2 learner group, the said effect was not found to vary as a function of proficiency in the L2. These findings inform of both L1 spoken word recognition models and L2 lexical processing accounts. In the following section, a discussion about the first type of models will be offered, followed by a discussion of L2 models. It is important to stress, however, that the following interpretations can be considered at least in an acoustic context with isolated words without the aid of any other syntactic, suprasegmental or pragmatic cues.

\section{L1 speakers}

The findings with native speakers support accounts of L1 spoken word recognition with a sequential activation of phonological and semantic information. In these models, such as the original (Marslen-Wilson, 1987; Marslen-Wilson \& Tyler, 1980; Marslen-Wilson \& Welsh, 
1978) and revised Cohort Model (Marslen-Wilson, 1990), the conceptual information of the word is accessed after a certain phonological threshold. In other words, there is a direct phonological mapping onto semantic representations, as phonology and semantics do not operate in parallel. Therefore, these claims involve the exclusion of a semantic layer in the spoken word recognition architecture.

In the current study, native speakers did not take a significantly longer amount of time to process a phonological sequence that activated morphologically related pairs (e.g., /frut/ activated fruto 'fruit' and fruta 'fruit') than a sequence that activated morphologically unrelated pairs (e.g., /pwert/ activated puerto and puerta). Therefore, the morphological root, and therefore the semantics, of the activated words in /frut/ (i.e., fruto, fruta) did not compete with each other, as they did not yield either inhibitory or facilitative effects. The first interpretation of the results is that they do not offer empirical evidence of a semantic layer in the word recognition process prior to reaching a phonological uniqueness point. In other words, the perception of phonetic features activates phonological sequences that match the acoustic signal and that may compete with each other with regard to their phonology, but not with their associated meaning. This is so because the meanings of the different activated candidates might not be activated in parallel before a recognition point. Additionally, semantic representations may only be accessed after only one candidate remains and, hence, the word has been recognized (i.e., after passing a recognition point). Even after the word is recognized, the two activated candidates prior to the recognition point might not compete for morphology or meaning, as one of the phonological candidates has already been selected and the other one discarded, thus never having had access to its meaning. A visual representation of this process can be found in Table 2.

\section{Table 2}


Activation of meaning according to the Cohort model 1 and 2

\begin{tabular}{ccc}
\hline Linear stage & Phonological sequence unfolded & Semantic representations \\
\hline 1 & $/ \mathrm{f} /$ & No meaning activation \\
2 & $/ \mathrm{fr} /$ & No meaning activation \\
3 & $/ \mathrm{fru} /$ & No meaning activation \\
4 & $/ \mathrm{frut} /$ & No meaning activation \\
5 & $/$ fruto/ & Meaning of 'fruit' activated \\
\hline
\end{tabular}

Another possible interpretation of the findings involves distributed models of L1 spoken word recognition. These models, such as the Distributed Cohort Model (Gaskell \& MarslenWilson, 1997, 2002), claim that as spoken words unfold, phonological candidates and their corresponding semantic representations are activated in parallel. The meanings of the phonological candidates are blended but become clear when only one candidate is left, and the word is finally recognized. Table 3 shows the semantic activation path according to this model. A phonological sequence with more than one candidate cannot facilitate the recognition of morphologically related words, but sequences with only one candidate do. It is unclear in this model, however, whether the blended semantic representations of the activated phonological candidates are linked to each phonological candidate, or whether there is a common node including the blended meaning of the two phonological candidates. This distinction, which might not be clear in the Distributed Cohort Model, is crucial for the interpretation of the findings of the current study.

\section{Table 3}


Activation of blended concepts according to the Distributed Cohort Model when listening to fruto 'fruit'

\begin{tabular}{ccl}
\hline Stage & $\begin{array}{c}\text { Phonological } \\
\text { representations }\end{array}$ & \multicolumn{1}{c}{ Semantic representations } \\
\hline 1 & $/ \mathrm{f} /$ & $\begin{array}{l}\text { Blended concepts of flor 'flower', flan 'flan', foto } \\
\text { 'photo', fruto 'fruit', fruta 'fruit', frambuesa } \\
\text { 'raspberry', Francia 'France', frugal 'frugal', etc. }\end{array}$ \\
& Blended concepts of fruto 'fruit', fruta 'fruit', \\
& frambuesa 'raspberry', Francia 'France', frugal \\
& 'frugal', etc. \\
& Blended concepts of fruto 'fruit', fruta 'fruit', \\
3 & frugal 'frugal', etc. \\
4 & Blended concepts of fruto 'fruit' and fruta 'fruit' \\
5 & /fruto/ & Concept of fruto 'fruit' \\
\hline
\end{tabular}

In the first scenario (i.e., each phonological candidate is linked to a blended semantic representation of both phonological candidates), it is clear that semantic competition effects are unable to emerge in morphologically unrelated minimal pairs (e.g., /mark/ activates marco 'frame' and marca 'brand') due to the meanings being unrelated. However, in morphologically related minimal pairs, the blended semantic representation for the meaning of each phonological candidate would still highly resemble the original meaning of each of the phonological candidates. Therefore, the blended meaning between fruto and fruta for the candidate fruto would be able to compete with the blended meaning between fruto and fruta for only other phonological candidate, fruta. This competition would yield either inhibitory or facilitative effects, although based on semantic priming studies, the latter type would be more likely to emerge. However, the present findings did not show this pattern, which suggests that the spoken word recognition architecture does not contemplate a blended meaning between the two 
phonological competitors being linked to each of the candidates. A visual representation of this first interpretation of the data based on the Distributed Cohort Model can be found in Figure 3.

\section{Figure 3}

First possible interpretation of the data based on the Distributed Cohort Model

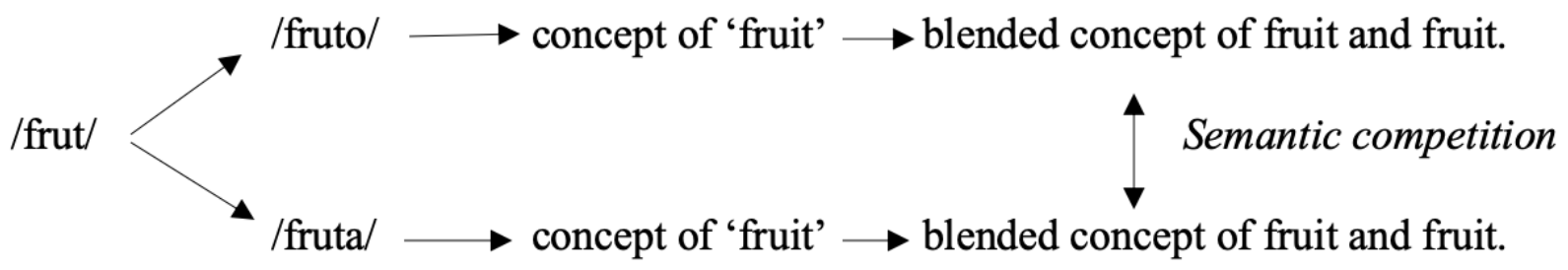

In the second scenario (i.e., the blended meaning of the two phonological competitors is located in one common node accessible to both competitors), the clarity of the content of the common node would depend on the morphological relatedness of the phonological candidates as in the first interpretation. However, a common semantic blend would not be able to compete with any other blend, as it is the only node that holds the semantic characteristics of the candidates. Therefore, no semantic competition effects would arise, not because of the inexistence of a semantic layer during the activation of more than one candidate, but because the blended semantic representations cannot compete with themselves. This interpretation can indeed explain the data in the current study. A visual representation of this interpretation can be found in Figure 4.

\section{Figure 4}

Second possible interpretation of the data based on the Distributed Cohort Model 


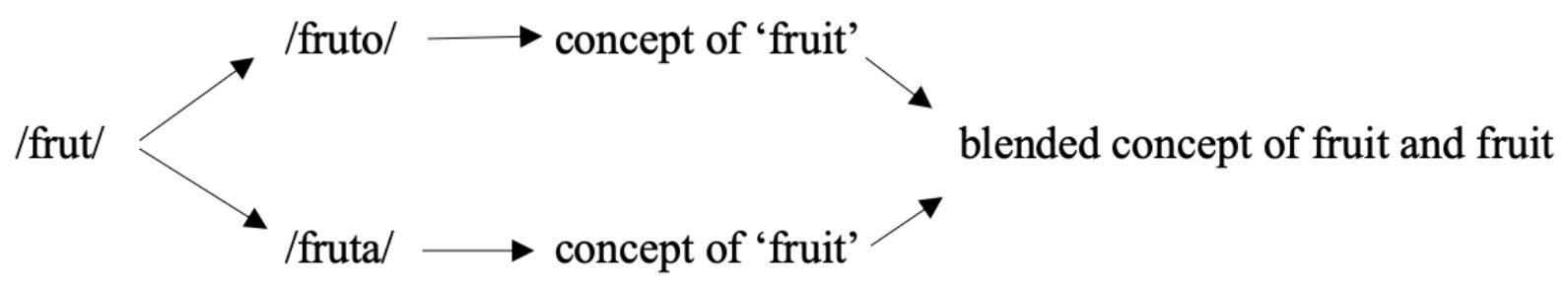

Finally, the finding of the present study that morphological relatedness effects may not arise before a recognition point in native speakers does not replicate those found using the priming paradigm (e.g., Gaskell \& Marslen-Wilson, 2002; Winther Balling \& Baayen, 2008; Zwitserlood, 1989). In the present investigation, participants may have accessed the candidates using metalinguistic strategies as well as online discard of candidates that did not match the input, due to the nature of the task (e.g., thinking whether the incomplete sequence was present in Spanish). The priming paradigm, on the other hand, may tap into conscious lexical knowledge to a lesser degree, thus eliciting word retrieval faster. Importantly, the study does not replicate the morphological competition effects found in studies using complex suffixed words (Winther Balling \& Baayen, 2008) as the stimuli used in the present study do not contain complex uniqueness points. It is also important to note that the lack of morphological competition in this study is informative about a very specific context of speech perception, namely the auditory recognition of isolated words without any context, as it is the case in lexical decision tasks. The aid of pragmatic, syntactic or suprasegmental information can indeed ease the access of semantic representations before the recognition point, such as in the case of linguistic prediction. This was the case, for example, in recent eye-tracking studies where Spanish monolinguals and English L2 learners of Spanish successfully predicted words such as /'pa.pa/ or /pa'pa/ ('potato' - 'father') 
(which are phonologically, but not phonetically identical) based on suprasegmental information of the first vowel (Lozano-Argüelles, Sagarra \& Casillas, 2020).

In sum, the L1 data suggests that Spanish native speakers recognized phonological sequences activating morphologically related pairs in a similar way than those activating morphologically unrelated ones. This result does not provide evidence of morphological competition prior to word recognition. This seems to support localist models in which meaning is accessed after a recognition point. Alternatively, the finding can also support distributed models in which each phonological candidate is linked to only one common semantic node with blended representations of the cohort.

\section{L2 speakers}

The findings from this study show that RTs for sound sequences activating morphologically related candidates were roughly the same as for those that activated morphologically unrelated candidates in English L2 learners of Spanish. Additionally, proficiency in the L2 did not seem to modulate this effect, as all three proficiency groups behaved comparatively similarly to one another in this regard.

The present results support the extension of the Cohort Model (Marslen-Wilson, 1987; Marslen-Wilson \& Tyler, 1980; Marslen-Wilson \& Welsh, 1978) and the revised Cohort Model (Marslen-Wilson, 1990) to bilingual populations. This type of account, known as the Bilingual Cohort Model (Blumenfeld \& Marian, 2007; Marian, 2000) explains that bilinguals also activate phonological cohorts that are mapped onto lexical representations after the incoming signal reaches a recognition point. In this sense, the Bilingual Cohort Model does not make any claims about the parallel activation of morphological and phonological representations before a certain threshold. This makes it a good fit for the data of the present study because once bilinguals 
recognize a word, the word cannot compete with other candidates either phonologically or morphologically, at least within-language. This prevents morphological relatedness effects from emerging. It should be noted, however, that one of the central claims of the Bilingual Cohort Model (i.e., words in both languages are activated in parallel), cannot be tested in this experiment, as the present study explores within-language competition only.

In addition, the study of within-language morphological relatedness effects might also be informative about morphological competition cross-linguistically, specifically in the case of cognates. Studies finding cross-linguistic cognate facilitation effects also report that this effect is greater the more phonological overlap between items, which suggests that phonology is responsible for competition effects cross-linguistically, while morphology might play a lesser role in facilitation effects. The study of cross-linguistic competition through cognates is thus difficult because it is almost impossible to isolate morphology by keeping phonology identical across languages. This was indeed possible in the current study through the within-language processes, as our stimuli were phonologically identical up to the recognition point and varied only in their morphological relationship. Given that this study found no evidence of withinlanguage morphological competition in bilinguals, the results could potentially support the notion that morphology might not be a major factor triggering facilitation effects crosslinguistically.

With regard to distributed models of L1 spoken word recognition, interpretations about the L2 data are similar to those of the L1 data. First, if each of the two phonological candidates has separate links to the blended meaning of both candidates, then within-language competition may arise. In this case, the Distributed Cohort Model would not be able to account for the data from the current study. Second, if the blended meanings are found in a common node accessible 
to both phonological competitors, morphological competition effects cannot emerge. In that scenario, the data from this study would support this account.

It is also worth noting that L2 learners of Spanish recognized spoken words significantly slower than Spanish monolinguals. Differences in recognition speed between the two groups have major implications for spoken word recognition and bilingual processing theories and can be explained in at least two different ways. First, L2 learners might be activating phonological candidates from their two languages, as the Bilingual Cohort Model suggests. The process of activating and discarding a larger number of competitors might in turn slow down the spoken word recognition process. Second, a significant difference in word recognition speed between monolinguals and L2 learners agrees with the predictions of the Revised Hierarchical Model (Kroll \& Stewart, 1994; Kroll et al., 2010). This account posits that the L2 lexicon has weak links with the conceptual level, unlike the L1. Some L2 words can be recognized through the equivalent translation from the L1 lexicon, which will connect to the conceptual level. The operation of moving from the L2 lexicon to the L1 lexicon to finally access meaning is a longer process than L1 word access, which may explain differences in word recognition between the two speaker groups.

In sum, the L2 data supports the extension of the revised Cohort Model to L2 populations. Furthermore, the interpretation of a common semantic layer common to all phonological candidates in a distributed spoken word recognition process can also explain the L2 data. In addition, the fact that L2 learners were slower at recognizing L2 words than monolinguals may support claims of parallel activation by the Bilingual Cohort Model and weak links between the L2 and the conceptual level as proposed by the Revised Hierarchical Model. 
Finally, the findings are informative about a qualitatively similar spoken word recognition architecture in L2 learners and their monolingual peers.

The study had certain limitations that might have influenced the results. First, the unprimed nature of the auditory lexical decision task might have hindered sufficient morphological activation of the phonological candidates, thus failing to capture potential morphological competition effects. This could potentially be a limitation because it is currently unknown whether unprimed lexical decision tasks differ from their primed versions with regard to the strength of lexical activation. Future studies should try to replicate the present findings using the priming paradigm and including phonologically identical stimuli varying in their morphological relatedness. Second, the results of the study are informative about how Spanish monolinguals and English L2 learners of Spanish recognize isolated spoken words in their L1 and the L2, respectively. The present findings cannot provide evidence of morphological competition in contexts were pragmatic, lexical or syntactic cues are available, such as in word recognition during sentence processing. Also, the results are revealing about the said population only. Future studies are encouraged to further explore the role of cue availability in sentence contexts in spoken word recognition, and to extend it to other languages.

\section{Conclusion}

The present study examined morphological competition effects during spoken word recognition in Spanish native speakers and in English L2 learners of Spanish. Previous studies investigated whether morphology modulates spoken word recognition in bilinguals crosslinguistically, but little evidence has been gathered on whether this also occurs within-language. Thus, this study should be taken as one of the first attempts to explore morphological relatedness effects on within-language L1 and L2 spoken word recognition, and the findings presented here 
are to be seen as suggestive rather than conclusive. Results revealed that both Spanish monolinguals and English L2 learners of Spanish processed phonological sequences activating morphologically related competitors similarly than those activating morphologically unrelated ones. Also, this result did not vary as a function of proficiency in the L2 in the case of L2 learners. These results are interpreted as a lack of evidence of morphological competition in spoken word recognition before reaching a recognition point. Taken together, the findings are consistent with models claiming that semantic representations are accessed after a recognition point (Marslen-Wilson, 1990) and distributed models where a semantic layer is located in one common node accessible to all phonological candidates (Gaskell \& Marslen-Wilson, 1997, 2002), which may prevent morphological competition between candidates prior to recognition. Furthermore, the findings support the extension of these models to L2 speaker populations, as the L2 spoken word recognition architecture seems to be qualitatively similar to that of native speakers. 


\section{Appendix}

Activated candidates given a phonological sequence prior to its recognition point

\section{Phonological competitors}

Masc.

Caño 'pipe'
Coco 'coconut'
Copo 'flake'

Cuadro 'painting'

Mango 'mango'

Marco 'frame'

Modo 'mode'

Palo 'stick'

Puerto 'harbor'

Punto 'dot'

Tallo 'stalk'

Velo 'veil'
Fem.

Caña 'rod'

Coca 'coca'

Copa 'cup'

Cuadra 'block'

Manga 'sleeve'

Marca 'brand'

Moda 'fashion'

Pala 'shovel'

Puerta 'door'

Punta 'tip'

Talla 'clothing size'

Vela 'candle'

Phonological and morphological competitors Masc. Fem.

Banca 'banking'

Barca 'small boat'

Bolsa 'bag'

Cesta 'basket'

Cinta 'tape'

Fruta 'fruit'

Gorra 'cap'

Huerto 'vegetable patch' Huerta 'vegetable garden'

Leño 'log'

Manto 'cloak'

Peso 'weight'

Ramo 'bouquet'
Leña 'firewood'

Manta 'blanket'

Pesa 'dumbbell'

Rama 'branch' 


\section{References}

Alemán Bañón, J., Fiorentino, R., \& Gabriele, A. (2018). Using event-related potentials to track morphosyntactic development in second language learners: The processing of number and gender agreement in Spanish. PloS one, 13(7), e0200791. https://doi.org/10.1371/journal.pone.0200791

Altvater-Mackensen, N., \& Mani, N. (2013). The impact of mispronunciations on toddler word recognition: Evidence for cascaded activation of semantically related words from mispronunciations of familiar words. Infancy, 18(6), 1030-1052. https://doi.org/10.1111/infa.12022

Bates, D., \& Maechler, M. (2009). 1me4: Linear Mixed-Effects Models Using S4 Classes. R package version 0.999375-32. http://CRAN.R-project.org/package=lme4.

Blumenfeld, H. K., \& Marian, V. (2007). Constraints on parallel activation in bilingual spoken language processing: Examining proficiency and lexical status using eye-tracking. Language and cognitive processes, 22(5), 633-660.

https://doi.org/10.1080/01690960601000746

Blumenfeld, H. K., \& Marian, V. (2011). Bilingualism influences inhibitory control in auditory comprehension. Cognition, 118(2), 245-257. https://doi.org/10.1016/j.cognition.2010.10.012

Buchanan, L., Westbury, C., \& Burgess, C. (2001). Characterizing semantic space: Neighborhood effects in word recognition. Psychonomic Bulletin \& Review, 8(3), 531544. https://doi.org/10.3758/BF03196189 
Coughlin, C. E., \& Tremblay, A. (2015). Morphological decomposition in native and non-native French speakers. Bilingualism: Language and cognition, 18(3), 524-542. https://doi.org/10.1017/S1366728914000200

Danguecan, A. N., \& Buchanan, L. (2016). Semantic neighborhood effects for abstract versus concrete words. Frontiers in psychology, 7, 1034. https://doi.org/10.3389/fpsyg.2016.01034

Dijkstra, T., Miwa, K., Brummelhuis, B., Sappelli, M., \& Baayen, H. (2010). How crosslanguage similarity and task demands affect cognate recognition. Journal of Memory and language, 62(3), 284-301. https://doi.org/10.1016/j.jml.2009.12.003

Durand López, E.M. (2021). Morphological processing and individual frequency effects in L1 and L2 Spanish. Lingua, 257, 103093. https://doi.org/10.1016/j.lingua.2021.103093

Gaskell, M. G., \& Marslen-Wilson, W. D. (1997). Integrating form and meaning: A distributed model of speech perception. Language and cognitive processes, 12(5-6), 613-656. https://doi.org/10.1080/016909697386646

Gaskell, M. G., \& Marslen-Wilson, W. D. (1999). Ambiguity, competition, and blending in spoken word recognition. Cognitive Science, 23(4), 439-462. https://doi.org/10.1207/s15516709cog2304_3

Gaskell, M. G., \& Marslen-Wilson, W. D. (2002). Representation and competition in the perception of spoken words. Cognitive psychology, 45(2), 220-266. https://doi.org/10.1016/S0010-0285(02)00003-8

Goh, W. D., Yap, M. J., Lau, M. C., Ng, M. M., \& Tan, L. C. (2016). Semantic richness effects in spoken word recognition: A lexical decision and semantic categorization megastudy. Frontiers in psychology, 7, 976. https://doi.org/10.3389/fpsyg.2016.00976 
Keuleers, E., \& Brysbaert, M. (2011). Detecting inherent bias in lexical decision experiments with the LD1NN algorithm. The Mental Lexicon, 6(1), 34-52. https://doi.org/10.1075/ml.6.1.02keu

Kroll, J. F., \& Stewart, E. (1994). Category interference in translation and picture naming: Evidence for asymmetric connections between bilingual memory representations. Journal of memory and language, 33(2), 149. https://doi.org/10.1006/jmla.1994.1008

Kroll, J. F., Van Hell, J. G., Tokowicz, N., \& Green, D. W. (2010). The Revised Hierarchical Model: A critical review and assessment. Bilingualism: Language and Cognition, 13(3), 373-381. 10.1017/S136672891000009X

Lozano-Argüelles, C., Sagarra, N., \& Casillas, J. V. (2020). Slowly but surely: Interpreting facilitates L2 morphological anticipation based on suprasegmental and segmental information. Bilingualism: Language and Cognition, 23(4), 752-762. $10.1017 / \mathrm{s} 1366728919000634$

Luce, P. A., \& Pisoni, D. B. (1998). Recognizing spoken words: The neighborhood activation model. Ear and hearing, 19(1), 1-36. 10.1097/00003446-199802000-00001

Marian, V. (2000). Bilingual language processing: Evidence from eye-tracking and functional neuroimaging. Ph.D. Dissertation, Cornell University. UMI Dissertation Services.

Marian, V., Blumenfeld, H. K., \& Kaushanskaya, M. (2007). The Language Experience and Proficiency Questionnaire (LEAP-Q): Assessing language profiles in bilinguals and multilinguals. Journal of Speech, Language, and Hearing Research, 50, 940-967. https://doi.org/10.1044/1092-4388(2007/067)

Marian, V., Chabal, S., Bartolotti, J., Bradley, K., \& Hernandez, A. E. (2014). Differential recruitment of executive control regions during phonological competition in 
monolinguals and bilinguals. Brain and language, 139, 108-117. https://doi.org/10.1016/j.bandl.2014.10.005

Marian, V., \& Spivey, M. (2003). Competing activation in bilingual language processing: Within-and between-language competition. Bilingualism: Language and Cognition, 6(2), 97-115. 10.1017/S1366728903001068

Marslen-Wilson, W., \& Tyler, L. K. (1980). The temporal structure of spoken language understanding. Cognition, 8(1), 1-71. https://doi.org/10.1016/0010-0277(80)90015-3

Marslen-Wilson, W. D., \& Welsh, A. (1978). Processing interactions and lexical access during word recognition in continuous speech. Cognitive psychology, 10(1), 29-63. https://doi.org/10.1016/0010-0285(78)90018-X

Marslen-Wilson, W. D. (1987). Functional parallelism in spoken word-recognition. Cognition, 25(1-2), 71-102. https://doi.org/10.1016/0010-0277(87)90005-9

Marslen-Wilson, W. D. (1990). Activation, competition, and frequency in lexical access. In G.T.M. Altman (Ed.), Cognitive Models of Speech Processing: Psycholinguistic and Computational Perspectives (pp. 148-172). Cambridge, MA: MIT Press.

McClelland, JL, \& Elman, JL. (1986). The TRACE model of speech perception. Cognitive Psychology, 18(1), 1-86. https://doi.org/10.1016/0010-0285(86)90015-0

Meade, G., Midgley, K. J., Dijkstra, T., \& Holcomb, P. J. (2018). Cross-language neighborhood effects in learners indicative of an integrated lexicon. Journal of cognitive neuroscience, 30(1), 70-85. https://doi.org/10.1162/jocn_a_01184

Mirman, D., \& Magnuson, J. S. (2009). Dynamics of activation of semantically similar concepts during spoken word recognition. Memory \& cognition, 37(7), 1026-1039. https://doi.org/10.3758/MC.37.7.1026 
Moss, H. E. (1997). The time course of activation of semantic information during spoken word recognition. Language and Cognitive processes, 12(5-6), 695-732. https://doi.org/10.1080/016909697386664

Norris, D. (1994). Shortlist: A connectionist model of continuous speech recognition. Cognition, 52(3), 189-234. https://doi.org/10.1016/0010-0277(94)90043-4

Norris, D., Cutler, A., McQueen, J. M., \& Butterfield, S. (2006). Phonological and conceptual activation in speech comprehension. Cognitive Psychology, 53(2), 146-193. https://doi.org/10.1016/j.cogpsych.2006.03.001

Pexman, P. M., Heard, A., Lloyd, E., \& Yap, M. J. (2017). The Calgary semantic decision project: concrete/abstract decision data for 10,000 English words. Behavior research methods, 49(2), 407-417. https://doi.org/10.3758/s13428-016-0720-6

Rosselli, M., Ardila, A., Jurado, M. B., \& Salvatierra, J. L. (2014). Cognate facilitation effect in balanced and non-balanced Spanish-English bilinguals using the Boston Naming Test. International Journal of Bilingualism, 18(6), 649-662. https://doi.org/10.1177/1367006912466313

Sagarra, N., \& Herschensohn, J. (2011). Proficiency and animacy effects on L2 gender agreement processes during comprehension. Language Learning, 61(1), 80-116. https://doi.org/10.1111/j.1467-9922.2010.00588.x

Santiago, F., Singh, P., \& Sri, L. (2017). Building Cognitive Applications with IBM Watson Services: Volume 6 Speech to Text and Text to Speech. IBM Redbooks.

Sebastián-Gallés, N., Cuetos, F., Carreiras, M., \& Martí-Antonin, M. (2000). LEXESP. Léxico informatizado del español. Publicacions de la Universitat de Barcelona. 
Slabakova, R., Kempchinsky, P., \& Rothman, J. (2012). Clitic-doubled left dislocation and focus fronting in L2 Spanish: A case of successful acquisition at the syntax-discourse interface. Second Language Research, 28(3), 319-348. https://doi.org/10.1177/0267658312447612

Vitevitch, M.S. \& Luce, P.A. (2004). A web-based interface to calculate phonotactic probability for words and nonwords in English. Behavior Research Methods, Instruments, and Computers, 36, 481-487. https://doi.org/10.3758/BF03195594

Vitevitch, M.S. \& Luce, P. (2016). Phonological neighborhood effects in spoken word perception and production. Annual Review of Linguistics, 2, 75-94. https://doi.org/10.1146/annurev-linguistics-030514-124832

Vitevitch, M.S., Stamer, M.K. \& Kieweg, D. (2012). The Beginning Spanish Lexicon: A Web based interface to calculate phonological similarity among Spanish words in adults learning Spanish as a foreign language. Second Language Research, 28, 103-112. https://doi.org/10.1177/0267658311432199

White, E. J., Titone, D., Genesee, F., \& Steinhauer, K. (2017). Phonological processing in late second language learners: The effects of proficiency and task. Bilingualism: Language and Cognition, 20(1), 162-183. https://doi.org/10.1017/S1366728915000620

Wingfield, A., Goodglass, H., \& Lindfield, K. C. (1997). Word recognition from acoustic onsets and acoustic offsets: Effects of cohort size and syllabic stress. Applied Psycholinguistics, 18(1), 85-100. https://doi.org/10.1017/S0142716400009887

Winther Balling, L., \& Harald Baayen, R. (2008). Morphological effects in auditory word recognition: Evidence from Danish. Language and Cognitive processes, 23(7-8), 11591190. https://doi.org/10.1080/01690960802201010 
Zwitserlood, P. (1989). The locus of the effects of sentential-semantic context in spoken-word processing. Cognition, 32(1), 25-64. https://doi.org/10.1016/0010-0277(89)90013-9 